\title{
Uso de terapia regenerativa com células-tronco da medula óssea em doenças cardiovasculares - perspectiva do hematologista
}

\author{
Regenerative therapy using bone marrow stem cells in cardiovascular diseases - The perspective of \\ the hematologist
}

Augusto C. A. Mota ${ }^{1}$
Milena B. P. Soares
Ricardo R. Santos

\begin{abstract}
O desenvolvimento de técnicas de transplante de órgãos sólidos e de medula óssea foi um dos mais fascinantes avanços da medicina no século XX. A virada do século XXI testemunha um desdobramento também fascinante e promissor desta modalidade terapêutica: o uso de células-tronco para regenerar tecidos lesados outrora considerados irreparáveis. Resultados encorajadores de inúmeros estudos com animais de experimentação impulsionaram grupos de diversos centros no mundo a iniciar estudos clínicos com transplante de células-tronco em várias doenças, particularmente as doenças cardiovasculares e neurológicas. Embora ainda estejamos algo distante de entender o mecanismo preciso pelo qual as células-tronco regeneram órgãos lesados, os estudos publicados até o presente momento, incluindo vários estudos envolvendo seres humanos, sugerem haver um beneficio real com esta terapia. O presente artigo pretende abordar os aspectos relevantes da terapia celular em doenças cardiovasculares, incluindo conceitos básicos sobre células-tronco, e os principais estudos de animais de experimentação e clínicos publicados até o presente. Rev. bras. hematol. hemoter. 2005;27(2):126-132.
\end{abstract}

Palavras-chave: Células-tronco; terapia celular; doenças cardiovasculares.

\section{Introdução}

A segunda metade do século XX foi marcada por fantásticos progressos na área médica, particularmente com relação a novos métodos diagnósticos e novas modalidades terapêuticas. Dentre os inúmeros avanços terapêuticos testemunhados, um dos mais notáveis foi o progresso na área de transplante de órgãos e, em particular, o emprego de célulastronco para a regeneração do sistema hematopoético. Tendo como base experimentos utilizando modelos animais, ${ }^{1}$ as experiências clínicas iniciais com a restauração da hematopoese através da infusão de células-tronco hematopoéticas ${ }^{2}$ conduziram ao emprego já bem estabelecido de transplante de medula óssea no tratamento de várias doenças hematológicas benignas $^{3-5}$ e malignas, ${ }^{6,7}$ bem como para alguns tumores sólidos. ${ }^{8}$ O reconhecimento do impacto desta nova modalidade terapêutica culminou com a concessão do Prêmio Nobel de Medicina e Fisiologia em 1990 a Joseph Murray e E Donall Thomas, pioneiros em transplante de órgãos e células.

Na virada do século XXI, um desdobramento da terapia de transplante de órgãos e células ganhou uma nova dimensão. Diferentemente dos conceitos existentes até então (órgãos inteiros sendo substituídos no caso dos transplantes de órgãos, ou células utilizadas para recompor a medula óssea após mieloablação com altas doses de quimioterapia, no caso do transplante de medula óssea), a terapia celular ou terapia regenerativa traz consigo um novo conceito de alterar o curso de lesões orgânicas. Através do uso de

${ }^{1}$ Hospital Santa Izabel da Santa Casa de Misericórdia da Bahia.

${ }^{2}$ Centro de Pesquisas Gonçalo Moniz, Fiocruz/BA.

Correspondência para: Augusto Mota

Hospital Santa Izabel - Coordenação de Ensino e Pesquisa

Praça Almeida Couto, 500

44.050-410 - Nazaré - Salvador-BA

E-mail:augusto.mota@meddi.com.br 
células-tronco provenientes de diferentes fontes, tem sido possível, pelo menos nos estudos iniciais já publicados, reverter quadros patológicos que outrora eram considerados irreversíveis. O presente artigo pretende rever os conceitos básicos desta nova modalidade terapêutica, bem como fazer uma sinopse dos dados clínicos já existentes na área de doenças cardiovasculares.

\section{Células-tronco}

As células-tronco são células indiferenciadas que têm a capacidade de se diferenciar em células altamente especializadas, ao mesmo tempo em que conseguem se manter no estado indiferenciado. O mecanismo pelo qual as célulastronco conseguem realizar esta dupla função (diferenciação mantendo uma reserva de células indiferenciadas) ainda não está completamente elucidado, embora alguns aspectos importantes já sejam conhecidos. Por exemplo, estudos utilizando tecnologia de análise genética com microchips (microarray) têm permitido, baseados no padrão de expressão gênica destas células, identificar algumas características básicas responsáveis pela manutenção do estado indiferenciado, que incluiriam a capacidade de responder ao hormônio do crescimento e à trombina, a integração com a matriz extracelular via integrina $\alpha_{6}-\beta_{1}$, a alta resistência ao estresse através do aumento da expressão de enzimas de reparo de DNA, entre outras. ${ }^{9}$ Além disso, várias proteínas de sinalização extracelular diferentes têm sido identificadas como tendo papel importante na manutenção do estado indiferenciado das células-tronco, tais como Bmi- $1,{ }^{10}$ Notch e Wnt, ${ }^{11}$ Tie2/Angiopoietina- $1{ }^{12}$ e Oct $4 .{ }^{13}$

\section{Células-tronco embrionárias}

As células-tronco embrionárias são obtidas da massa celular interna do embrião e possuem a capacidade de se diferenciar em tipos celulares dos três folhetos embrionários (endoderma, mesoderma e ectoderma) tanto in vitro ${ }^{14,15}$ quanto in vivo, ${ }^{16}$ o que demonstra a sua pluripotencialidade. $\mathrm{O}$ isolamento de células-tronco embrionárias humanas foi reportado pela primeira vez em $1998,{ }^{17}$ e desde então tem sido observado um crescimento exponencial no número de experimentos com estas células, envolvendo melhoria nas condições de cultura, ${ }^{18}$ manipulação genética ${ }^{19}$ e indução de diferenciação em diferentes tecidos. ${ }^{20-22}$ Apesar de serem consideradas as mais promissoras das células-tronco em função da sua pluripotencialidade, o conhecimento atual ainda não permite a produção de derivados de célulastronco embrionárias suficientemente puros e funcionais para uso clínico em terapia regenerativa, existindo o perigo real de formação de tumores resultantes da diferenciação desorganizada destas células. ${ }^{23}$ Além disso, o uso terapêutico destas células tem gerado embates éticos calorosos, justamente em função do fato de as células serem obtidas de embriões humanos. ${ }^{24}$

\section{Células-tronco de cordão umbilical}

O sangue de cordão umbilical é rico em células-tronco, o que tem permitido a sua utilização clínica como fonte alternativa à medula óssea em transplante de medula óssea tanto em crianças ${ }^{25}$ quanto em adultos. ${ }^{26,27}$ Estudos recentes têm demonstrado que estas células possuem também um potencial regenerador de tecidos lesados, como demonstrado em modelos experimentais de infarto agudo do miocárdio ${ }^{28,29} \mathrm{e}$ de acidente vascular cerebral. ${ }^{30}$ Embora haja ainda um longo caminho a ser trilhado em relação à expansão in vitro destas células com o intuito de se obter um número maior para a sua utilização em transplantes e em terapias celulares, dados recentes indicam que elas poderão ser cultivadas e modificadas geneticamente in vitro com este propósito. ${ }^{31} \mathrm{O}$ fato de serem mais facilmente obtidas, a partir de um material que é normalmente descartado, torna sua utilização menos controversa do ponto de vista ético, embora este aspecto ainda esteja longe de ser um ponto pacífico. ${ }^{32}$

\section{Células-tronco de medula óssea}

Estas células são de especial interesse para a medicina regenerativa. Existem evidências substanciais de que célulastronco da medula óssea circulam para o sangue periférico e de volta para a medula óssea, em um processo fisiológico estreitamente regulado por uma complexa interação de citocinas. ${ }^{33,34}$ Observações recentes de quimerismo cardíaco após transplante de medula óssea podem ser em parte explicadas por este fenômeno fisiológico. ${ }^{35,36}$ Além disso, evidências indicam que células-tronco, possivelmente originadas da medula óssea, circulam no sangue periférico e se dirigem para tecidos lesados tanto no contexto de doenças hematológicas ${ }^{37}$ quanto não hematológicas. ${ }^{38}$ Além de todos estes atributos, as células-tronco da medula óssea são obtidas de maneira relativamente fácil, tornando-as excelentes candidatas na utilização em terapias regenerativas. Os trabalhos utilizando terapias com células de medula óssea serão discutidos mais extensamente a seguir.

\section{Terapias com células-tronco de medula óssea}

O estudo de terapias com células-tronco no reparo de tecidos ou órgãos lesados em pacientes portadores de doenças crônico-degenerativas é bastante recente. A primeira descoberta da capacidade das células-tronco de medula óssea em se diferenciarem em células mais especializadas foi reportada em 1998. Em um modelo experimental de lesão muscular induzida quimicamente em camundongos scid/bg, Ferrari e colaboradores demonstraram que células-tronco (precursores miogênicos) da medula óssea de animais adultos podiam migrar para a região muscular lesada e se diferenciar em músculo esquelético. ${ }^{39}$ Desde esta descoberta, vários outros grupos publicaram evidências de diferenciação de células-tronco de medula óssea de animais adultos em cardiomiócitos, ${ }^{40}$ células neurais, ${ }^{41,42}$ hepatócitos ${ }^{43,44}$ dentre outras ${ }^{45}$ Estes 
achados sinalizavam para uma mudança de paradigma, em que tecidos considerados pós-mitóticos (ou seja, sem capacidade regenerativa) poderiam ser reparados por células precursoras provenientes possivelmente da medula óssea. Por não envolver as mesmas questões filosóficas, éticas e religiosas observadas com a utilização de células-tronco embrionárias, a utilização de células de medula óssea de indivíduos adultos abriu um novo horizonte na medicina reparadora, ou regenerativa, onde não há possibilidade de rejeição imunológica (já que as células são autólogas) nem a necessidade de estoque de células em bancos de tecidos (já que o estoque aparentemente é inesgotável). Mais ainda, as evidências preliminares sugerem que esta nova modalidade terapêutica poderá ser usada em uma vasta gama de doenças crônico-degenerativas, muitas das quais com opções terapêuticas limitadas (quando existentes).

Dentre as doenças crônico-degenerativas passíveis de serem tratadas com células-tronco, as doenças cardiovasculares constituem seguramente as mais extensivamente estudadas até o presente momento. $\mathrm{O}$ número de trabalhos envolvendo o uso de células-tronco para regenerar miocárdio (e conseqüentemente melhorar a função cardíaca) em animais de experimentação é considerável. A tabela 1 sumariza os principais estudos de células-tronco em modelos experimentais de doença cardiovascular isquêmica (modelo mais utilizado), publicados até o presente momento.

O primeiro estudo experimental sugerindo haver diferenciação de células-tronco de medula óssea em cardiomiócitos foi reportado por Orlic e colaboradores ${ }^{40}$ Células obtidas de medula óssea de camundongos machos transgênicos para a proteína fluorescente verde e separadas por métodos imunomagnéticos $\left(\mathrm{Lin}^{-}, \mathrm{c}-\mathrm{Kit}^{+}\right)$foram injetadas diretamente no miocárdio de camundongos fêmeas C57BL/6, por via transepicárdica, três a cinco horas após a oclusão da artéria coronária. Quando comparados com os animais infartados e não tratados com células-tronco, os dados mostraram melhora significativa nos animais tratados com relação aos parâmetros de função ventricular analisados, bem como com relação à espessura da parede ventricular, sugerindo que fibras musculares teriam sido formadas em função do procedimento. Além disso, a análise da expressão de alguns marcadores indicaram que as novas células formadas eram "funcionalmente competentes", incluindo a expressão de conexina 43 , uma proteína responsável pela conexão intercelular e acoplamento elétrico entre os cardiomiócitos. Depois deste estudo, vários grupos reportaram estudos animais usando células-tronco em cardiopatia isquêmica, mas os resultados têm sido controversos com relação à eficácia e à capacidade de diferenciação das células-tronco em cardiomiócitos $^{46-52}$ (Tabela 1).

Lastreados nestes resultados promissores em estudos com animais de experimentação, vários grupos iniciaram estudos empregando células-tronco em doenças cardiovasculares em seres humanos. Como pode ser observado na Tabela 2, os trabalhos envolvendo seres humanos publicados até o presente são consideravelmente mais heterogêneos do ponto de vista metodológico, quando comparado ao que se observa com os estudos de animais de experimentação. Por exemplo, as células-tronco nestes estudos têm sido obtidas das fontes mais variadas, como aspirado de medula óssea, aférese de sangue periférico após mobilização com fator de crescimento, bem como com o uso isolado de fator de crescimento. Além disso, os protocolos de separação e manipulação das células pós-coleta também têm sido bastante variados, dificultando a comparação entre os diferentes estudos. Os marcadores de superfície utilizados para

\begin{tabular}{|c|c|c|c|c|c|c|}
\hline \multicolumn{7}{|c|}{$\begin{array}{c}\text { Tabela } 1 \\
\text { Sumário dos estudos pré-clínicos de terapia com células-tronco de medula óssea em cardiopatia isquêmica. }\end{array}$} \\
\hline $\begin{array}{c}\text { Autor } \\
\text { Ano (n) }\end{array}$ & Espécie & $\begin{array}{c}\text { Modelo } \\
\text { experimental }\end{array}$ & $\begin{array}{l}\text { No de células } \\
\text { infundidas }\end{array}$ & Separação/ Manipulação & $\begin{array}{l}\text { Caracterização } \\
\text { imunofenotípica }\end{array}$ & Via de administração \\
\hline $\begin{array}{c}\text { Orlic } \\
2001(40)\end{array}$ & Camundongo & IAM & $3 \times 10^{4}$ a $2 \times 10^{5}$ & $\begin{array}{l}\text { Separação magnética por } \\
\text { citometria de fluxo }\end{array}$ & Lin-/cKit+ & $\begin{array}{l}\text { Injeção miocárdica } \\
\text { direta transepicárdica }\end{array}$ \\
\hline $\begin{array}{c}\text { Orlic } \\
2001(46)\end{array}$ & Camundongo & IAM & NR & $\begin{array}{c}\text { Mobilização para sangue } \\
\text { periférico }\end{array}$ & Lin-/cKit+ (presumido) & $\begin{array}{l}\text { Mobilização para } \\
\text { sangue periférico }\end{array}$ \\
\hline $\begin{array}{l}\text { Jackson } \\
2001(47)\end{array}$ & Camundongo & IAM & $2 \times 10^{3}$ & $\begin{array}{l}\text { Separação por } \\
\text { citometria de fluxo }\end{array}$ & cKit+/CD31+ & Migração espontânea \\
\hline $\begin{array}{l}\text { Hamano } \\
2002(48)\end{array}$ & Cão & IAM (30 dias) & $4 \times 10^{7}$ & $\begin{array}{l}\text { Gradiente de densidade } \\
\text { (meio Mono-poly) }\end{array}$ & NR & $\begin{array}{l}\text { Injeção miocárdica } \\
\text { direta transepicárdica }\end{array}$ \\
\hline $\begin{array}{c}\text { Balsam } \\
2004(49)\end{array}$ & Camundongo & IAM & $6 \times 10^{5}$ & $\begin{array}{l}\text { Separação magnética por } \\
\text { citometria de fluxo }\end{array}$ & Lin-/cKit+ & $\begin{array}{l}\text { Injeção miocárdica } \\
\text { direta transepicárdica }\end{array}$ \\
\hline $\begin{array}{l}\text { Nygren } \\
2004(50)\end{array}$ & Camundongo & IAM & $2 \times 10^{5}$ & $\begin{array}{l}\text { Separação magnética por } \\
\text { citometria de fluxo }\end{array}$ & Lin-/cKit+ & $\begin{array}{l}\text { Injeção miocárdica } \\
\text { direta transepicárdica }\end{array}$ \\
\hline $\begin{array}{c}\text { Murry } \\
2004(51)\end{array}$ & Camundongo & IAM & $\begin{array}{c}1 \times 10^{7} \text { (para recuperação } \\
\text { hematológica, antes do IAM). }\end{array}$ & $\begin{array}{l}\text { Gradiente de densidade; } \\
\text { Separação magnética por } \\
\text { citometria de fluxo. }\end{array}$ & Lin-/cKit+ & $\begin{array}{l}\text { Injeção miocárdica } \\
\text { direta transepicárdica }\end{array}$ \\
\hline $\begin{array}{l}\text { Olivares, } \\
2004(52)\end{array}$ & Rato & IAM & $1-3 \times 10^{5}$ & $\begin{array}{l}\text { Gradiente de densidade/ } \\
\text { Cultura durante uma semana }\end{array}$ & CD34-/CD45- & $\begin{array}{l}\text { Injeção miocárdica } \\
\text { direta transepicárdica }\end{array}$ \\
\hline
\end{tabular}


caracterização das células que estão sendo infundidas também diferem entre os estudos, alguns reportando inúmeros marcadores celulares ${ }^{53}$ e outros reportando apenas um marcador. ${ }^{57}$ De maneira semelhante, os métodos de implantação das células-tronco no miocárdio têm consistido de injeção intracoronária, injeção direta miocárdica transepicárdica sob visualização direta durante cirurgia cardíaca a céu aberto, e injeção miocárdica transendocárdica guiada por mapeamento eletromecânico do coração. Esta última metodologia foi empregada em um estudo pioneiro realizado por pesquisadores do Hospital Pró-Cardíaco, no Rio de Janeiro, e da Universidade Federal do Rio de Janeiro, em colaboração com o Texas Heart Institute. ${ }^{59}$ Neste estudo, as células foram coletadas da medula óssea de pacientes portadores de doença isquêmica crônica refratária à terapia clínica otimizada. As zonas de miocárdio hibernante identificadas pelo mapeamento eletromecânico foram escolhidas para receber ao todo $3 \mathrm{~mL}$ de uma suspensão de células contendo ao todo $2,5 \times 10^{7}$ células.

Outro estudo pioneiro no Brasil na área de cardiologia foi realizado na Bahia, fruto de uma cooperação entre o Hospital Santa Izabel da Santa Casa de Misericórdia da Bahia e o Centro de Pesquisas Gonçalo Moniz - Fiocruz/BA. Utilizando o modelo de cardiopatia chagásica, em que camundongos com doença de Chagas crônica foram tratados com células mononucleares de medula óssea de camundongos consangüíneos por via endovenosa, demonstrou-se uma redução significativa tanto no número de células inflamatórias como no grau de fibrose no miocárdio nos animais tratados quando comparados aos controles. ${ }^{60}$ Estes dados sugeriam haver um papel para o uso das células-tronco obtidas da medula óssea no tratamento da doença de Chagas. Baseado nestes

\begin{tabular}{|c|c|c|c|c|c|c|c|}
\hline \multicolumn{8}{|c|}{$\begin{array}{l}\text { Tabela } 2 \\
\text { células-tronco de medula óssea em cardiopatia isquêmica }\end{array}$} \\
\hline $\begin{array}{l}\text { Autor } \\
\text { Ano }(n)\end{array}$ & $\begin{array}{c}\text { Cardiopatia } \\
\text { ( } \mathrm{N}^{\circ} \text { de } \\
\text { pacientes/ } \\
\text { controles) } \\
\end{array}$ & $\begin{array}{l}\text { Fonte } \\
\text { de CT }\end{array}$ & $\begin{array}{l}\text { Volume }(\mathrm{ml}) / \\
\mathrm{N}^{\circ} \text { de células } \\
\text { infundidas) }\end{array}$ & $\begin{array}{l}\text { Separação/ } \\
\text { Manipulação }\end{array}$ & $\begin{array}{l}\text { Caracterização } \\
\text { imunofenotipica }\end{array}$ & $\begin{array}{c}\text { Via de } \\
\text { administração }\end{array}$ & Desfechos analisados \\
\hline $\begin{array}{l}\text { Strauer } \\
2002 \\
(53)\end{array}$ & $\begin{array}{l}\text { Isquêmica } \\
\text { aguda } \\
(20 / 10)\end{array}$ & MO & $\begin{array}{l}40 / \text { entre } 9 \times 10^{6} \\
\text { e } 2,8 \times 10^{7} \text { ) }\end{array}$ & $\begin{array}{l}\text { Gradiente de } \\
\text { ficoll/Cultivo } \\
\text { de } 24 \text { horas }\end{array}$ & $\begin{array}{c}\text { CD34 }-2,1 \% \\
\text { AC133 }-0,65 \%\end{array}$ & $\begin{array}{l}\text { Intracoronária, } \\
\text { com balão } \\
\text { insuflado }\end{array}$ & $\begin{array}{c}\text { Acinesia, discinesia e } \\
\text { hipocinesia na zona de } \\
\text { infarto }-\downarrow^{*} \text {; velocidade de } \\
\text { movimentação de parede }-\uparrow^{*} \text {; } \\
\text { fração de ejeção }-\uparrow \# ; \\
\text { defeito de perfusão }-\downarrow^{*} \text {. } \\
\text { SEGUIMENTO - }\end{array}$ \\
\hline $\begin{array}{l}\text { Assmus } \\
2002 \\
(54)\end{array}$ & $\begin{array}{l}\text { Isquêmica } \\
\text { aguda } \\
(20 / 0)\end{array}$ & MO vs SP & $\begin{array}{c}M O-N R / 7 \\
35 \times 10^{6} \\
S P-250 / N R\end{array}$ & $\begin{array}{l}\text { MO - gradiente } \\
\text { de densidade } \\
\text { com ficoll } \\
\text { não manipulada SP - } \\
\text { aférese/ expansão } \\
\text { ex-vivo durante } \\
3 \text { dias }\end{array}$ & $\begin{array}{c}\mathrm{MO}-\mathrm{CD} 34^{+} / \mathrm{CD} 45^{+}-2,8 \% \\
\mathrm{CD} 34^{+} / \mathrm{AC} 133^{+}-1 \% \\
\mathrm{CD} 34^{+} / \mathrm{KDR}^{+}-0,2 \% \\
\mathrm{SP}-90 \% \text { com } \\
\text { marcadores endoteliais }\end{array}$ & $\begin{array}{l}\text { Intracoronária, } \\
\text { com balão } \\
\text { insuflado }\end{array}$ & $\begin{array}{c}\text { FE global }-\uparrow^{*} ; \\
\text { movimentação de parede } \\
\text { na área infartada }-\uparrow^{*} ; \\
\text { reserva de fluxo } \\
\text { coronariano }-\uparrow^{*} ; \text { captação do } \\
\text { traçador na cintilografia } \\
\text { miocárdica }-\uparrow^{*} \text {. } \\
\text { SEGUIMENTO }-4 \text { meses }\end{array}$ \\
\hline $\begin{array}{l}\text { Stamm } \\
2003 \\
(55)\end{array}$ & $\begin{array}{l}\text { Isquêmica } \\
\text { aguda } \\
(6 / 0)\end{array}$ & MO & $\begin{array}{c}85-195 / \\
\text { entre } 1,18 \times 10^{5} \mathrm{e} \\
1,57 \times 10^{6}\end{array}$ & $\begin{array}{c}\text { Gradiente de } \\
\text { densidade com } \\
\text { ficoll/purificação } \\
\text { por separação magnética }\end{array}$ & $\mathrm{CD} 34^{-/ \mathrm{AC}} 133^{+}$ & $\begin{array}{c}\text { Injeção miocárdica } \\
\text { sob visualização } \\
\text { direta após } \\
\text { cirurgia de revascularização }\end{array}$ & $\begin{array}{c}\text { FE }-\uparrow \text {; acinesia - } \leftrightarrow \text {; } \\
\text { perfusão miocárdica por } \\
\text { cintilografia }-\uparrow \\
\text { SEGUIMENTO - } 3 \text { meses }\end{array}$ \\
\hline $\begin{array}{c}\text { Tse } \\
2003 \\
(56)\end{array}$ & $\begin{array}{l}\text { Isquêmica } \\
\text { crônica } \\
(8 / 0)\end{array}$ & MO & 40/NR & - & $\begin{array}{l}\mathrm{CD}^{2} 4^{+}-3,2 \% ; \mathrm{CD}^{+}-7,6 \% \\
\text { CD } 11 \mathrm{~b}^{+} / \mathrm{D} 15^{+}-43,7 \%\end{array}$ & $\begin{array}{l}\text { Injeção miocárdica } \\
\text { transendocárdica guiada por } \\
\text { mapeamento eletromecânico } \\
\text { (NOGA) }\end{array}$ & $\begin{array}{c}N^{\circ} \text { episódios de } \\
\text { angina/semana }-\downarrow * ; \\
N^{\circ} \text { de comprimidos de } \\
\text { nitroglicerina } \\
\text { usados/semana }-\downarrow^{*} \text {; FE }-\leftrightarrow \text {. } \\
\text { SEGUIMENTO }-3 \text { meses }\end{array}$ \\
\hline $\begin{array}{l}\text { Perin } \\
2003 \\
(59)\end{array}$ & $\begin{array}{l}\text { Isquêmica } \\
\text { crônica } \\
(14 / 7)\end{array}$ & MO & $50 / 5,7 \times 10^{4}$ & $\begin{array}{l}\text { MO - gradiente } \\
\text { de densidade } \\
\text { com Ficoll// } \\
\text { não manipulada }\end{array}$ & CD45 $5^{\text {Low } / C D 34^{+}}$ & $\begin{array}{l}\text { Injeção miocárdica } \\
\text { transendocárdica }\end{array}$ & $\begin{array}{l}\text { FE - } \uparrow^{*} \text {; Classe funcional - } \\
\downarrow^{*} \text {; CCSAS - } \downarrow^{*} \text {; VSF }-\downarrow \text {; } \\
\text { defeito de perfusão na } \\
\text { cintilografia }-\downarrow^{*}\end{array}$ \\
\hline $\begin{array}{l}\text { Wollert } \\
2004 \\
(57)\end{array}$ & $\begin{array}{l}\text { Isquêmica } \\
\text { aguda } \\
(60 / 30)\end{array}$ & MO & $128 / 2,4 \times 10^{9}$ & - & $\mathrm{CD}_{3} 4^{+}\left(9,5 \times 10^{6}\right)$ & $\begin{array}{l}\text { Intracoronária, com balão } \\
\text { insuflado }\end{array}$ & $\begin{array}{c}\text { FE }-\uparrow^{*} \text {; movimentação da } \\
\text { parede na área } \\
\text { infartada }-\uparrow * ; \text { troponina } T-\leftrightarrow ; \\
\text { arritmias }-\leftrightarrow \\
\text { SEGUIMENTO }-6 \text { meses }\end{array}$ \\
\hline $\begin{array}{r}\text { Kang } \\
2004 \\
(58)\end{array}$ & $\begin{array}{l}\text { Isquêmica } \\
\text { aguda } \\
(10 / 10 / 7)\end{array}$ & $\begin{array}{l}\text { SP vs } \\
\text { G-CSF vs } \\
\text { controle }\end{array}$ & $\mathrm{NR} / 1 \times 10^{9}$ & - & $\mathrm{CD}_{3} 4^{+}\left(7 \times 10^{6}\right)$ & Intracoronária & $\begin{array}{c}\text { FE }-\uparrow^{*}(\mathrm{CT}), \leftrightarrow(\mathrm{FC})-\leftrightarrow ; \\
\text { movimentação da parede } \\
\text { na área infartada }-\leftrightarrow \\
(\mathrm{CT} \text { e FC); áreas de } \\
\text { hipoperfusão na } \\
\text { cintilografia }-\downarrow^{*}(\mathrm{CT}), \leftrightarrow(\mathrm{FC}) \\
\text { reserva de fluxo } \\
\text { coronariano }-\uparrow^{*}(\mathrm{CT}), \leftrightarrow(\mathrm{FC}) \\
\text { SEGUIMENTO }-6 \text { meses }\end{array}$ \\
\hline
\end{tabular}


dados foi iniciado um estudo de fase I envolvendo pacientes portadores de ICC decorrente de miocardiopatia chagásica, em classe funcional III e IV da New York Heart Association. Estes pacientes recebiam as células-tronco diretamente na circulação coronária via cateterismo cardíaco, após exclusão de doença arterial coronariana pela coronariografia. As células mononucleares foram obtidas de cerca de $50 \mathrm{~mL}$ de medula óssea dos próprios pacientes, aspirados em pontos diferentes de ambas as cristas ilíacas e separadas por gradiente de densidade com Ficoll. Trinta pacientes já foram submetidos ao procedimento, não tendo sido observadas até o presente momento complicações relacionadas aos procedimentos de coleta e cateterismo cardíaco. Os resultados obtidos dos pacientes tratados e com tempo de seguimento de no mínimo seis meses $(\mathrm{N}=10)$ indicam uma melhora significativa tanto na função cardíaca quanto na qualidade de vida. ${ }^{61}$

Apesar dos resultados até o momento promissores utilizando células de medula óssea em terapias celulares para cardiopatias, ainda não se sabe quais os tipos de células que são importantes para o processo de reparo dos tecidos. Da mesma forma ainda não se sabe como nem quantos fatores solúveis participam do processo de recrutamento e indução da diferenciação destas células após sua implantação nos tecidos os quais se deseja reparar. Muito ainda precisa ser esclarecido também acerca do mecanismo pelo qual as célulastronco regeneram tecidos lesados. Os dois principais mecanismos reconhecidos até o momento são a transdiferenciação e a fusão celular. ${ }^{62-64}$ Embora alguns estudos tenham mostrado a geração de células diferenciadas a partir de célulastronco de medula óssea ou de sangue de cordão umbilical, seja por fusão celular ou transdiferenciação, a regeneração de tecidos lesados pode não depender da presença destas células no tecido lesado.

Em um estudo recente, Borlogan e colaboradores, trabalhando com modelo experimental de acidente vascular cerebral em ratos, demonstraram que células-tronco do cordão umbilical humano causam melhora funcional no déficit neurológico apesar de não migrarem para o cérebro, possivelmente através da produção de fatores tróficos neuroprotetores. ${ }^{65}$

Evidências recentes sugerem que também em cardiopatia isquêmica a presença de células possa não ser necessária para haver a regeneração miocárdica. Gnecchi e colaboradores reportaram os resultados de um estudo experimental utilizando sobrenadante de cultura (meio condicionado) de três tipos de células mesenquimais, todas submetidas a condições de hipóxia: células não manipuladas, células com expressão do gene da proteína fluorescente verde e células com superexpressão do gene Akt. Neste modelo de cardiopatia isquêmica aguda em ratos, o meio condicionado foi injetado na área ao redor do infarto 30 minutos após a oclusão da artéria coronária. No coração dos animais tratados com meio condicionado por células mesenquimais superexpressando Akt foi observada uma redução significa- tiva na área de infarto e no índice apoptótico, quando comparado com os animais tratados com meio condicionado procedente de culturas de células não manipuladas e de células com expressão da proteína fluoresecente verde.$^{66}$ Estas evidências mais recentes sugerem que ainda temos um longo caminho a percorrer até que tenhamos um entendimento satisfatório sobre o assunto.

Em linha com estes achados mais recentes, uma estratégia que já vem sendo testada para enriquecer a população celular a ser utilizada na terapia é o isolamento de células mesenquimais derivadas da medula óssea. Células-tronco mesenquimais são células clonogênicas não-hematopoiéticas presentes na medula óssea, capazes de se diferenciar em múltiplos tipos celulares de origem mesodérmica e nãomesodérmica. Por serem isoladas e cultivadas in vitro de maneira relativamente fácil e pelo seu potencial de diferenciação, protocolos clínicos utilizando células mesenquimais da medula óssea para o tratamento de doenças sistêmicas, implantação no sítio de tecidos lesados e como veículos para genes em terapias gênicas já estão sendo testados. ${ }^{67}$

\section{Considerações finais}

A área de doenças cardiovasculares é hoje a mais estudada quanto ao potencial terapêutico das células-tronco de medula óssea, ainda havendo muito a ser elucidado com relação a qual seja a melhor célula, a melhor fonte, a melhor forma de implantação no miocárdio e o melhor momento na evolução de cada doença em particular. No entanto, outras áreas já estão também sendo alvo de estudos com esta fonte de células, como doenças neurodegenerativas, auto-imunes, hepatopatias e retinopatias.

Embora os resultados alcançados em várias áreas sejam animadores, pouco se sabe sobre os mecanismos de atuação destas células, quais populações celulares são importantes e quais os fatores necessários para o recrutamento e função destas células. A melhor compreensão destes fenômenos deverá contribuir para o desenvolvimento de estratégias terapêuticas mais eficazes e menos invasivas para doenças crônico-degenerativas.

\section{Abstract}

Solid organ and bone marrow transplantation were two of the most fascinating treatment modalities developed in the second half of the past century. At the turn of the 21st century the use of stem cells emerge as a potential therapeutic option for diseases previously thought to be irreversible. The promising results of animal studies paved the way for several groups all around the world to investigate the role of stem cell therapy in the clinical setting. The results of these clinical trials have been published over the last couple of years, most of which dealing with cardiovascular and neurological disorders. The results of the trials published thus far are encouraging (both animal and clinical) and suggest that there may be a real benefit with this therapy, yet we are still considerably distant from a 
reasonable understanding of the mechanism of tissue repair by stem cells. The present article will briefly review relevant aspects of the so called regenerative medicine, focusing on cardiovascular disorders. Rev. bras. hematol. hemoter. 2005;27(2):126-132.

\section{Key words: Stem cell; cell therapy; cardiovascular disease}

\section{Referências Bibliográficas}

1. Merwin RM, Congdon CC. Repopulation of hematopoietic tissues and blood in lethally $\mathrm{x}$-irradiated mice by homologous bone-marrow cells. J Natl Cancer Inst 1957;19(5):875-84.

2. Thomas ED, Lochte HL Jr, Cannon JH, et al. Supralethal whole body irradiation and isologous marrow transplantation in man. $\mathrm{J}$ Clin Invest 1959;38:1709-16.

3. Gaziev J, Lucarelli G. Stem cell transplantation for thalassemia. Reprod Biomed Online 2005;10(1):111-5

4. Walters MC, Storb R, Patience M, et al. Impact of bone marrow transplantation for symptomatic sickle cell disease: an interim report. Blood 2000;95(6):1918-24.

5. Gluckman E, Auerbach AD, Horowitz HH, et al. Bone marrow transplantation for Fanconi's anemia. Blood 1995;86(7):2.856-62.

6. Child JA, Morgan GJ, Davies FE, et al. High-dose chemotherapy with stem-cell rescue for multiple myeloma. N Eng J Med 2003; 348(19):1875-83.

7. Holmberg LA, Stewart FM. Hematopoietic stem cell transplantation for non Hodgkin's lymphoma. Oncology (Huntingt) 2003;17(5): 627-32.

8. Childs R, Barrett J. Nonmyeloablative stem cell transplantation for solid tumors: expanding the application of allogeneic immunotherapy. Semin Hematol 2002;39(1):63-71.

9. Ramalho-Santos M, Soonsang Y, Matsuzaki Y, et al. "Stemness": Transcriptional profiling of embryonic and adult stem cells. Science 2002;298:597-600.

10. Park I-K, Dalong Q, Kiel M, et al. Bmi-1 is required for maintenance of adult self-renewing haematopoietic stem cells. Nature 2003; 423:302-5.

11. Duncan AW, Rattis FM, DiMascio LN, et al. Integration of Notch and Wnt signaling in hematopoietic stem cell maintenance. Nat Immunol 2005;6(3):314-22.

12. Arai F, Hirao A, Ohmura M, et al. Tie2/Angiopoietin-1 signaling regulates hematopoietic stem cell quiescence in the bone marrow niche. Cell 2004;118:149-61.

13. Niwa H, Miyazaki J, Smith AG. Quantitative expression of Oct-3/ 4 defines differentiation, dedifferentiation or self-renewal of ES cells. Nat Genet 2000;24:372-8.

14. Evans MJ, Kaufman MH. Establishment in culture of pluripotential cells from mouse embryos. Nature 1981;292:154-6.

15. Martin G. Isolation of a pluripotent cell line from early mouse embryos cultures in medium conditioned by teratocarcinoma stem cells. Proc Natl Acad Sci USA 1981;78:7634-7638.

16. Nagy A, Rossant J, Nagy R, et al. Derivation of completely cell culture-derived mice from early passage embryonic stem cells. Proc Natl Acad Sci USA 1993;90:8424-8.

17. Thomson JA, Itskovitz-Eldor J, Shapiro SS, et al. Embryonic stem cell line from human blastocysts. Science 1998;282:1145-7.

18. Amit M, Margulets V, Segev H, et al. Human feeder layers for human embryonic stem cells. Biol Reprod 2003;68:2150-6.

19. Zwaka TP, Thomson JA. Homologous recombination in human embryonic stem cells. Nat Biotech 2003;21:319-21.

20. Kehat I, Amit M, Gepstein A, et al. Development of cardiomyocytes from human ES cells. Methods in Enzymology 2003; 365:461-73.
21. Schulz TS, Palmarini GM, Noggle SA, et al. Directed neuronal differentiation of human embryonic stem cells. BMC Neuroscience $2003 ; 4 ; 27-41$.

22. Assady S, Maor G, Amit M, et al. Insulin production by embryonic stem cells. Diabetes 2001;50:1691-7.

23. Erdo F, Buhrle C, Blunk J, et al. Host-dependent tumorigenesis of embryonic stem cell transplantation in experimental stroke. J Cereb Blood Flow Metab 2003;23:780-5.

24. Lachmann P. Stem cell research - why is it regarded as a threat? EMBO Rep 2001;2:165-8.

25. Gluckman E, Rocha V. Cord blood transplantation for children with acute leukemia: a Eurocord registry analysis. Blood Cells Mol Dis 2004;33(3):271-3.

26. Laughlin MJ, Eapen M, Rubinstein P, et al. Outcomes after transplantation of cord blood or bone marrow from unrelated donors in adults with leukemia. N Engl J Med 2004;351:2.265-75.

27. Rocha V, Labopin M, Sanz G, et al. Transplants of umbilical-cord blood or bone marrow from unrelated donors in adults with acute leukemia. N Engl J Med 2004;351:2276-85.

28. Ma N, Stamm C, Kaminski A, et al. Human cord blood cells induce angiogenesis following myocardial infarction in NOD/scid mice. Cardiovasc Res 2005;66:45-54.

29. Hirata Y, Sata M, Motomura N, et al. Human umbilical cord blood cells improve cardiac function after myocardial infarction. Biochem Biophys Res Comm 2005;327:609-14.

30. Vendrame M, Cassady J, Newcomb J, et al. Infusion of human umbilical cord blood cells in a rat model of stroke dose-dependently rescues behavioral deficits and reduces infarct volume. Stroke 2004; $35: 2390-5$.

31. Lee MW, Yang MS, Park JS, et al. Isolation of mesenchymal stem cells from cryopreserved human umbilical cord blood. Int J Hematol 2005;81:126-30.

32. Terry LM, Campbell A. Protecting the interests of the child bone marrow donor. Med Law 2004;23:805-19.

33. Wright DE, Wagers AJ, Gulati AP, et al. Physiological migration of hematopoietic stem and progenitor cells. Science 2001;294:1.933-6.

34. Petit I, Goichberg P, Spiegel A, et al. Atypical PKC- regulates SDF-1-mediated migration and development of human $\mathrm{CD}^{-} 4^{+}$progenitor cells. J Clin Invest 2005;115:168-76.

35. Quaini F, Urbanek K, Beltrami AP, et al. Quimerism of the transplanted heart. N Engl J Med 2002;346:5-15.

36. Deb A, Wang S, Skelding KA, et al. Bone marrow-derived cardiomyocytes are present in adult human heart - a study of gender-mismatched bone marrow transplantation patients. Circulation 2003;107:1247-9.

37. Xu M, Bruno E, Chao J, et al. The constitutive mobilization of bone marrow-repopulating cells into the peripheral blood in idiopathic myelofibrosis. Blood 2005;105:1699-705.

38. Abe S, Boyer C, Liu X, et al. Cells derived from the circulation contribute to the repair of lung injury. Am J Resp Crit Care Med 2004; 170:1158-63.

39. Ferrari G, Cusela-De Angelis G, Coletta M, et al. Muscle regeneration by bone marrow-derived myogenic progenitors. Science 1998; 279:1528-30

40. Orlic D, Kajstura J, Chimenti S, et al. Bone marrow cells regenerate infracted myocardium. Nature 2001;410:701-5.

41. Mezey E, Chandross KJ, Harta G, et al. Turning blood into brain: cells bearing neuronal antigens generated in vivo from bone marrow. Science 2000;290:1779-82.

42. Brazelton TR, Rossi FMV, Keshet GI, et al. From marrow to brain: expression of neuronal phenotype in adult mice. Science 2000; 290:1775-9.

43. Petersen BE, Bowen WC, Patrene KD, et al. Bone marrow as a potential source of hepatic oval cells. Science 1999;284:1.168-70. 
44. Lagasse E, Connors H, Al-Dhalimy M, et al. Purified hematopoietic stem cells can differentiate into hepatocytes in vivo. Nat Med 2000;6:1229-34.

45. Krause DS, Theise ND, Collector MI, et al. Multi-organ, multilineage, engraftment by a single bone marrow-derived stem cell. Cell 2001;105:369-77.

46. Orlic D, Kajstura J, Chimenti S. Mobilized bone marrow cells repair the infracted heart, improving function and survival. Proc Natl Acad Sci USA 2001;98:10344-9.

47. Jackson KA, Majka SM, Wang H, et al. Regeneration of ischemic cardiac muscle and vascular endothelium by adult stem cells. J Clin Invest 2001:107:1395-402.

48. Hamano K, Li T-S, Kobayashi T, et al. Therapeutic angiogenesis induced by local autologous bone marrow cell implantation. Ann Thorac Surg 2002:73:1210-5.

49. Balsam LB, Wagers AJ, Christensen JL, et al. Haematopoietic stem cells adopt haematopoietic fates in ischaemic myocardium. Nature 2004;428:668-73.

50. Nygren JM, Jovinge S, Breitbach M, et al. Bone marrow-derived hematopoietic cells regenerate cardiomyocyte at a low frequency through cell fusion, but not transdifferentiation. Nat Med 2004; 10:494-500.

51. Murry CE, Soonpaa MH, Reinecke H, et al. Haematopoietic stem cells do not transdifferentiate into cardiac myocytes in myocardial infarcts. Nature 2004;428:664-8.

52. Olivares EL, Ribeiro VP, Werneck de Castro JPS, et al. Bone marrow stromal cells improve cardiac performance in healed infarcted rat hearts. Am J Physiol 2004;287:464-70.

53. Strauer BE, Brehm M, Zeus T, et al. Repair of infracted myocardium by autologous intracoronary mononuclear bone marrow cell transplantation in humans. Circulation 2002;106:1913-8.

54. Assmus B, Schächinger V, Teupe C, et al. Transplantation of progenitor cells and regeneration enhancement in acute myocardial infarction. (TOPCARE-AMI). Circulation 2002; 106:3009-17.

55. Stam C, Westphal B, Kleine H-D, et al. Autologous bone marrow stem cell transplantation for myocardial regeneration. Lancet 2003;361:45-6.

56. Tse H-F, Kwong Y-L, Chan JKF, et al. Angiogenesis in ischaemic myocardium by intramyocardial autologous bone marrow mononuclear cell implantation. Lancet 2003;361:47-9.

57. Wollert KC, Meyer GP, Lotz J, et al. Intracoronary autologous bone-marrow cell transfer after myocardial infarction: the BOOST randomized controlled clinical trial. Lancet 2004; 364:141-8.

58. Kang H-J, Kim, H-S, Zhang S-Y, et al. Effects of intracoronary infusion of peripheral blood stem-cells mobilized with granulocytecolony stimulating factor on left ventricular systolic function and restenosis after coronary stenting in myocardial infarction: the MAGIC cell randomized clinical trial. Lancet 2004;363:751-6.

59. Perin EC, Dohmann HFR, Borojevic R, et al. Transendocardial, autologous bone marrow cell transplantation for severe, chronic ischemic heart failure. Circulation 2003;107:2294-302.

60. Soares MBP, Lima RS, Rocha LL, et al. Transplanted bone marrow cells repair heart tissue and reduce myocarditis in chronic chagasic mice. Am J Pathol 2004;164:441-7.

61. Vilas-Boas F, Feitosa G, Soares M, et al. Transplante autólogo de células de medula óssea por via coronária é seguro e potencialmente eficaz em pacientes com forma avançada de insuficiência cardíaca por doença de Chagas. Rev Chil Cardiol 2004;23:280 (abstract).

62. Burke ZD, Tosh D. Therapeutic potential of transdifferentiated cells. Clin Sci, 2005;108:309-21.

63. Oh H, Bradfute SB, Gallardo TD, et al. Cardiac progenitor cells from adult myocardium: homing, differentiation and fusion after infarction. Proc Natl Acad Sci USA, 2003;100:12313-8.
64. Zhang S, Wang D, Estrov Z, et al. Both cell fusion and transdifferentiation account for the transformation of peripheral blood CD34-positive cells into cardiomyocytes in vivo. Circulation, 2004;110:3803-7.

65. Borlogan CV, Hadman M, Sanberg CD, et al. Central nervous system entry of peripherally injected umbilical cord blood cells is not required for neuroprotection in stroke. Stroke 2004; 35:2385-9.

66. Gnecchi M, He H, Liang OD, et al. Paracrine action accounts for marked protection of ischemic heart by Akt-modified mesenchymal stem cells. Nat Med 2005;11:367-8.

67. Kassem M. Mesenchymal stem cells: biological characteristics and potential clinical applications. Cloning Stem Cells 2004; 6(4):369-74

Avaliação: Editor e dois revisores externos Conflito de interesse: não declarado

Recebido: 02/05/2005

Aceito após modificações: 10/06/2005 